\title{
INCIDENCE AND CLINICAL SIGNIFICANCE OF HIGH GRADE PROSTATIC INTRAEPITHELIAL NEOPLASIA IN TURP SPECIFIMENS
}

\section{B. Pavan Kumar*}

Imran Ali

\section{Anwar Miya}

\section{Kishan}

Assistant Professor, Department Of Pathology, Kakastiya Medical College, Telangana, India. * Corresponding Author

Assistant Professor, Department Of Pathology, Kakastiya Medical College, Telangana, India.

Associate Professor, Department Of Pathology, Kakastiya Medical College, Telangana, India.

Professor \& Head Of Department Of Pathology, Kakastiya Medical College, Telangana, India.

ABSTRACT BACKGROUND: PIN is a well known precancerous condition of prostatic carcinoma. Transurethral resection of prostate has become the most prominent and the easiest way, to morphologically evaluate lesions of PIN. But clinicians are sometimes confused by the grading that is given in the report. So there is a need to define the diagnostic criteria and differential diagnosis of PIN using newer diagnostic techniques to assist in the better diagnosis and grading.

AIMS AND OBJECTIVES: To evaluate whether the diagnostic criteria can be defined PIN and using newer techniques for PIN grading to improve the clinical management of patients with prostatic lesions.

MATERIALS AND METHODS: This study will be done in the Department of Pathology MGM Hospitals, Warangal for a period of 2 years and includes consecutive cases of TURP specimens from the patients who present with obstructive symptoms as a major clinical presentation and correlated with PSA levels.

INCLULSION CRITERIA: Patients who present with obstructive symptoms as a major clinical presentation.

RESULTS:

1. 160 cases of TURP specimens were studied out of which 53 (33.12\%) cases are PIN. BPH -78 (48/74\%), PC-15 (9.37\%), SM-14 (8.75\%)

2. Majority cases are low grade PIN 34 out of 53 cases (21.25\%) High Grade PIN 19 out of 53cases. (11.87\%)

3. High Grade PIN and prostatic Carcinoma shared increased incidence and severity with advancing age in the study. Majority of HG PIN cases in our study noted in (70-79 years of age)

4. The risk of carcinoma is more in cases of High Grade PIN (68.42\%) than in low grade PIN (17.64\%)

5. This warrants are need for repeat prostatic biopsies to diagnose the invasive carcinoma in patient with High grade PIN.

KEYWORDS : Transurethral Resection Of Prostate.

\section{INTRODUCTION}

Prostatic intraepithelial neoplasis (PIN) refers to the precancerous end of a morphologic spectrum involving cellular proliferation within prostatic ducts, ductules and acini. Individuals who have high grade PIN on biopsy need to be watched very carefully because they are very likely over the next several years to actually have prostate cancer.

High-grade PIN (HGPIN) on Transurethral resection of prostate (TURP) is relatively uncommon and is diagnosed in an elderly population. Patients with HGPIN on TURP appear to be at increased risk of developing prostatic carcinoma, although not to the same degree as patients with HG PIN on needle biopsy HGPIN, a marker for increased risk for ultimately being diagnosed with prostatic cancer and is now accepted as the most likely pre invasive stage of adenocarcinoma. It is predominately a disease of elderly.

Both HGPIN and prostaic carcinoma share in increased incidence, severity with advancing age and with high rates of occurrence in the peripheral zones of prostate. As high grade PIN has a high predicative value as a marker for adenocarninoma, its identification warrants repeat biopsy for concurrent or subsequent invasive carcinoma. The only method of detection is biopsy.

Transurethral resection of prostate has become the most prominent and the existent way to morphological evaluation of lesion of PIN. But clinicians are sometimes confused by the grading that is given in the report. So there is a need to define the diagnostic criteria and differential diagnosis of PIN using newer diagnostic techniques to assist in the better diagnosis and grading.

PIN does not significantly elevate serum prostate specific antigen concentration or its derivatives and cannot be detected by ultrasound. The clinical importance of recognizing PIN is based on its strong association with prostatic carcinoma.PIN no apparent influence on serum PSA concentration and its not apparently visible by current imagining techniques.

\section{MATERIAL AND METHODS}

This is a hospital based prospective study done on TURP chips obtained from 160 patients attending the outpatient department of urology, Kakatiya Medical College, Warangal 2018-20. This study was done in the Dept of Pathology, Kakatiya Medical College, Warangal, Telangana.

Clinical data were collected in prescribed proforma meeting the objectives of the study. TURP chips were preserved in $10 \%$ formalin and allowed to fix for 24 hours. Paraffin wax embedding was done followed by tissue sectioning and staining with Haemetoxyline and Esoin (H\&E) for study under light microscope.

\section{INCLUSION CRITERIA}

The Study group includes all the patients from the age group 40 to 89 years.

\section{EXCLUSION CRITERIA}

The following categories are excluded from the study.

1. The cases which were clinically suspected to be neoplasm's but histological proved otherwise (inflammatory 
lesion, Non neoplastic Lesions).

2. Known cases prostatic carcinoma on treatment.

3. Patients who left the hospitals against medical advice.

A case proforma was prepared for each patient and all the subjects selected for this study were studied in detail with particulars reference.

\section{GRADING OF PIN}

The cores were graded based on histophatological findings into 2 grades (Low and High) and the result were analyzed.

\section{Follow up of cases}

Cases reported as low grade PIN on TURP specimens are followed for a period of 2 years. Cases reported as high PIN on TURP specimens are subjected for total prostatectomy.

\section{RESULTS}

The present study was carried out from Feb 2018 to Feb 2020 at Kakatiya Medical college Warangal.

Table: 1 Distribution Of Prostatic Lesions By Age Group

\begin{tabular}{|c|c|c|c|c|c|c|c|c|c|c|}
\hline Age & $\begin{array}{c}\text { BPH } \\
\text { No of } \\
\text { cases }\end{array}$ & $\begin{array}{c}\text { \% } \\
\text { No.of } \\
\text { cases }\end{array}$ & $\begin{array}{c}\text { LGPIN } \\
\text { No.of } \\
\text { cases }\end{array}$ & $\begin{array}{c}\text { HGPIN } \\
\text { No.of } \\
\text { csaes }\end{array}$ & $\%$ & $\begin{array}{c}\text { PC } \\
\text { No.of } \\
\text { cases }\end{array}$ & $\%$ \\
\hline $40-49$ & 6 & 3.74 & 3 & 1.87 & 3 & 1.87 & 2 & 1.25 & 3 & 1.87 \\
\hline $50-59$ & 11 & 6.87 & 4 & 2.5 & 6 & 3.75 & 4 & 2.5 & 1 & 0.62 \\
\hline $60-69$ & 36 & 22.49 & 3 & 1.87 & 12 & 7.52 & 4 & 2.5 & 6 & 3.75 \\
\hline $70-79$ & 17 & 10.62 & 3 & 1.87 & 12 & 7.5 & 9 & 5.62 & 5 & 3.12 \\
\hline $80-89$ & 8 & 4.94 & 1 & 0.62 & 1 & 0.62 & 0 & 0 & 0 & 0 \\
\hline Total & 78 & 48.66 & 14 & 8.73 & 34 & 21.26 & 19 & 11.87 & 15 & 9.37 \\
\hline
\end{tabular}

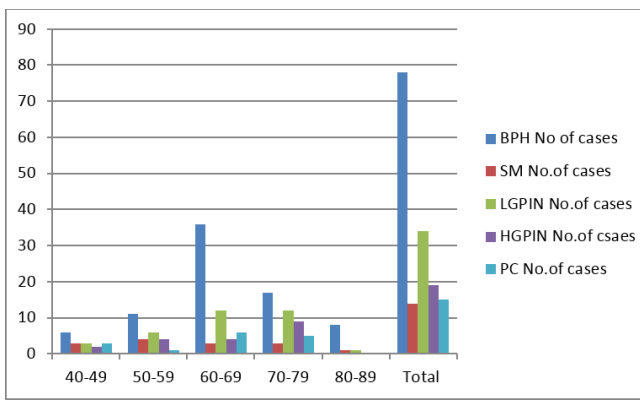

Graph-I Distribution Of Prostatic Lesions By Age Group

Majority 5.62\% of HGPIN cases in our study noted in (70-79) years of age) followed by $2.5 \%$ in (60-69 years) and the least incidence $1.25 \%$ in age group (40-49\%) No case was reported in the age group ( $80-89$ years).

Table-2 Various Lesions Of Prostate

\begin{tabular}{|l|c|c|}
\hline Lesions of the Prostate & No.of Cases & Percentage \\
\hline BPH & 78 & $48.75 \%$ \\
\hline Squamous Metaplasia & 14 & $8.75 \%$ \\
\hline LGPIN & 34 & $21.25 \%$ \\
\hline HGPIN & 19 & $11.87 \%$ \\
\hline Prostatic Carcinoma & 15 & $9.37 \%$ \\
\hline
\end{tabular}

Majority cases are BPH $48.75 \%$ followed by Low grade PIN $21.25 \%$ but the least are Squomous meta Plasia $8.75 \%$. the incidence of High grade PIN is $11.87 \%$

\section{No.of Cases}

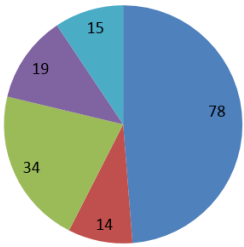

$$
\begin{aligned}
& \text { - } \text { BPH } \\
& \text { - Squamous Metaplasia } \\
& \text { - LGPIN } \\
& \text { - HGPIN } \\
& \text { - Prostatic Carcinoma }
\end{aligned}
$$

Graph 2: Various Lesions Of Prostate
Majority cases are BPH $48.75 \%$ followed by Low grade PIN $21.25 \%$ but the least are Squamous meta plasia $8.75 \%$. The incidence of High grade PIN is $11.87 \%$

Table-3 Grades Of PIN

\begin{tabular}{|l|l|l|}
\hline Grade of PIN & No.of Cases & Percentage \\
\hline LGPIN & 34 & $64.16 \%$ \\
\hline HGPIN & 19 & $35.84 \%$ \\
\hline Total & 53 & $100 \%$ \\
\hline
\end{tabular}

Majority are low grade PIN (64.16\%) and $35.84 \%$ are High grade PIN

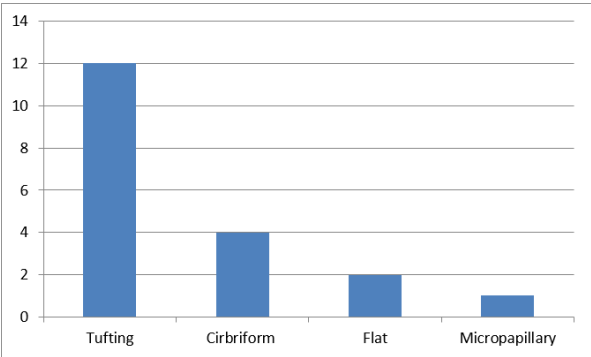

Graph-3: Microscopic Patterns Of PIN

The most common pattern PIN was the tufting (TF) pattern followed by cribriform (CF)

Table 4 Number Of Cases Of Carcinoma Among Various Grades Of PIN

\begin{tabular}{|c|c|c|c|}
\hline Grade of PIN & No.of cases & $\begin{array}{c}\text { No.of cases of } \\
\text { Malignancy }\end{array}$ & Percentage \\
\hline Low & 34 & 6 & $17.64 \%$ \\
\hline High & 19 & 13 & $68.42 \%$ \\
\hline Total & 53 & 19 & $35.84 \%$ \\
\hline
\end{tabular}

The carcinoma developed in $17.64 \%$ cases of LPGIN and $68.42 \%$ cases of HGIN.

Table :5 Incidence Of PIN In Cases Prostates With And Without Prostatic Carcinoma

\begin{tabular}{|c|c|c|c|}
\hline Studies & $\begin{array}{c}\text { No.of prostates } \\
\text { examined }\end{array}$ & $\begin{array}{c}\text { PIN without } \\
\text { carcinoma } \\
\text { (\%PIN) }\end{array}$ & $\begin{array}{c}\text { PIN with } \\
\text { Carcinoma } \\
\text { (\% PIN) }\end{array}$ \\
\hline $\begin{array}{c}\text { MC Neal \& } \\
\text { Bostwick (1986) }\end{array}$ & 200 & 43 & 82 \\
\hline Horinger W(2001) & 1077 & 4.7 & 61.4 \\
\hline Present Study & 160 & 64.16 & 35.84 \\
\hline
\end{tabular}

Table 6: Incidents Of HGPIN In Prostates With Carcinoma

\begin{tabular}{|c|c|}
\hline Authors & $\begin{array}{c}\text { Incidence of HGPIN with } \\
\text { prostatic adenocarcinoma\% }\end{array}$ \\
\hline Mc Neal and Bostwick (1986) & 33 \\
\hline Troncoso et al (1989) & 72 \\
\hline Qian et al (1995) & 100 \\
\hline W.Horinger (2002) & 61.4 \\
\hline Present Study & $68.42 \%$ \\
\hline
\end{tabular}

The incidence of PIN various considerably in different studies probably because histological diagnosis of LGPIN shows subjective variation and many studies. Do not report LG PIN.

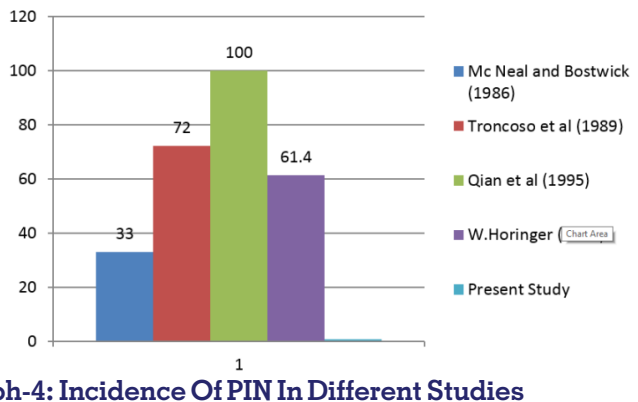




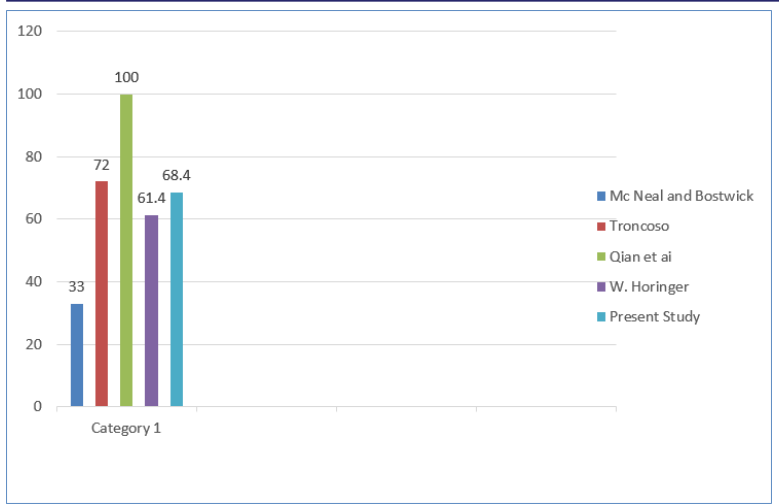

\section{OBSERVATIONS}

1. 160 cases of TURP specimens were studied, out of which $53(33.12 \%)$ cases are PIN

2. Patients with symptoms of obstruction (Hesitancy, poor flow, intermittent stream, dribbling) were included.

3. The presence of Ductal/Acinar epithelial changes including nuclear enlargement, prominent nucleoli, chromatin alteration, luminal complexity is an easy way to identify the PIN.

4. HGPIN shows marked nuclear enlargement, prominent eosinophilic nucleoli and increased chromatin compared to low grade PIN.

5. Majority cases are LGPIN-34 out of 53 cases $(21.25 \%) \&$ the HGPIN are 19 out of 53 ( $11.87 \%$ )

6. HGPIN and prostatic carcinoma shared increased incidence and severity with advancing age in the study. Majority of HGPIN cases in our study noted in ( $70-79$ years of age).

7. The risk of carcinoma is more in case of High grade PIN ( $68.42 \%$ ) than in low grade PIN (17.64\%) which is similar to other studies.

8. This warrants the need for repeat prostatic biopsies to diagnose the invasive carcinoma in patients with High grade PIN.

9. Relation of HGPIN to Carcinoma like, $68.42 \%$ association in the present study.

\section{DISCUSSION}

1. High grade prostatic intraepithelial neoplasis (PIN) is the most likely precursor of invasive prostatic adenocarcinoma. The incidence and clinical significance of this lesion have not been previously defined in specimens from transurethral resections of the prostate (TURP).

2. High grade PIN is the most likely precursor of prostatic adenocarcinoma, according to virtually all available evidence.

3. The clinical importance of recognizing PIN is based on its strong association with prostatic carcinoma. PIN has a high predictive value as a marker for adenocarcinoma, and its identification in biopsy specimens of the prostate warrants further search for concurrent invasive carcinoma. Studies to date have not determined whether PIN remains stable, regresses, or progresses, although the implication is that it can progress.

4. In the present study out of 160 specimens examined 53 cases showed PIN 34 cases were LGPIN, whereas 19 cases were HGPIN, LGPIN was characterized by epithelial crowding and stratification with anisonucleosis but no prominent nucleoli was observed.

5. High grade PIN was characterized by pronounced epithelial crowding and stratification, nuclear enlarging, hyperchromasia with prominent nucleoli, None of these lesions showed disruption of basal cell layer and basement membrane.

6. In our study PIN was seen most commonly in the age group of 70-79 years with a common symptoms of frequency, incomplete voiding and dysuria. In the study done by Mc Neal Bostwick frequency of PIN was highest in the age group 60-69 years. In other studies the mean age of PIN was 65 years.

7. In this study, the risk of carcinoma is more in case of High grade PIN (68.4\%) than in low grade PIN (17.64\%) which is similar to others studies.

8. There is a risk of finding a carcinoma on segment biopsies over 2 years follow up period.

9. The four main patterns of HGPIN are tufting, micro papillary, cribriform and flat. The tufting pattern is most common, although most cases have multiple patterns.

10. There is no known clinically important difference among the architectural petterns of HGPIN and this recognition appear to be only of diagnostic utility.

11. In this study, high risk of coexistent cancer was seen mostly in cribrifom pattern.

12. While some report suggest that HGPIN might result is an elevation of serum total PSA or higher values of free PSA than prostate cancer, no convincing evidence to correlate the presence of HGPIN with serum PSA has been found by others.

13. Therefore, if a man with an elevated serum PSA has isolated HGPIN on needle biopsy, a repeat prostate needle biopsy might be necessary to rule out other conditions causing PSA elevation, particularly prostate cancer.

14. Serum levels of PSA were frequently elevated in patients with PIN ranging from 0.3 to $22.3 \mathrm{mg} / \mathrm{ml}$ (mean 4.0). In the present study, they showed normal levels $(<4 \mathrm{ng} / \mathrm{ml})$. But cases of HGPIN associated with prostatic carnoma had high levels of PSA ( $>12 \mathrm{ng} / \mathrm{ml}$ )

\section{CONCLUSIONS}

1. The overall incidence of PIN in TURP specimens was $33.12 \%$

2. Prostatic adenocarcinoma was diagnosed most commonly in HGPIN

3. As prostatic intraepithelial neolasia is a precursor lesion for prostatic carcinoma, it needs to be detected as early as possible.

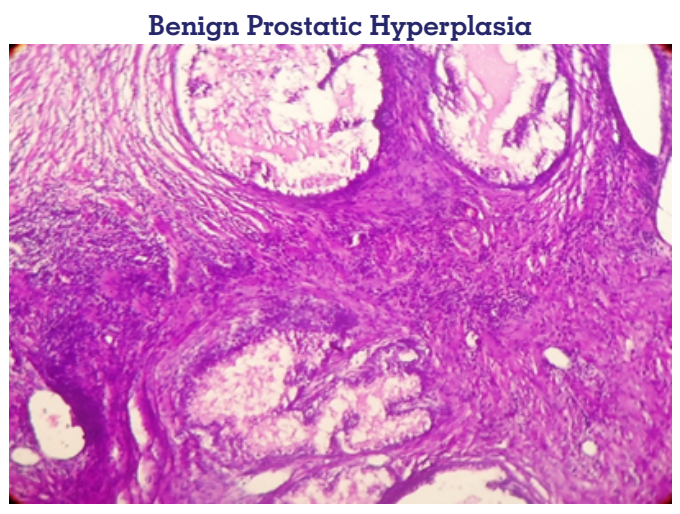

$\mathrm{H} \& \mathrm{E} 10 \mathrm{X}$

Fig.l. BPH showing hyperplasic glandular \& stromal components

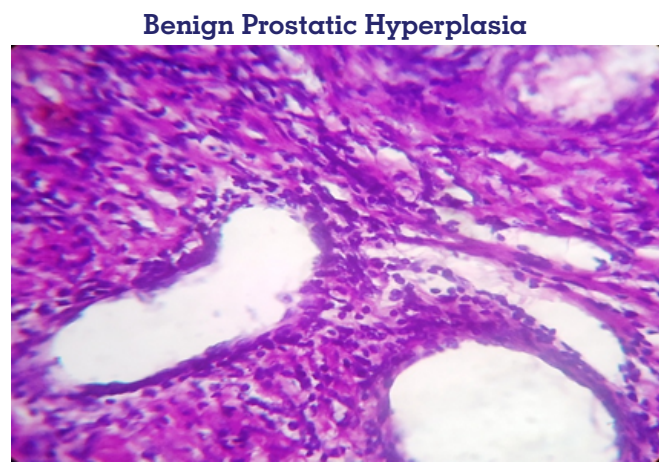

$\mathrm{H} \& \mathrm{E} 40 \mathrm{X}$

Fig.2. BPH is shows hyper plastic glands lined by cells with abundant clear cytoplasm and small round basally located nuclei. 


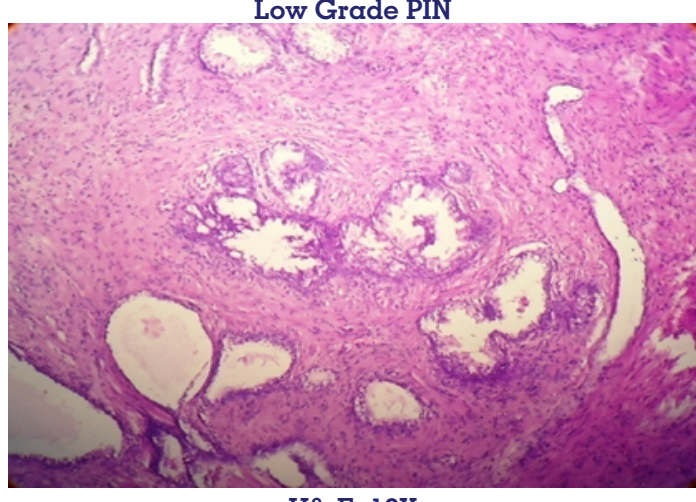

$\mathrm{H} \& \mathrm{E}, 10 \mathrm{X}$

Fin No.3 LGPIN showing epithelial crowding and stratification with anisonucleosis.

Low Grade PIN

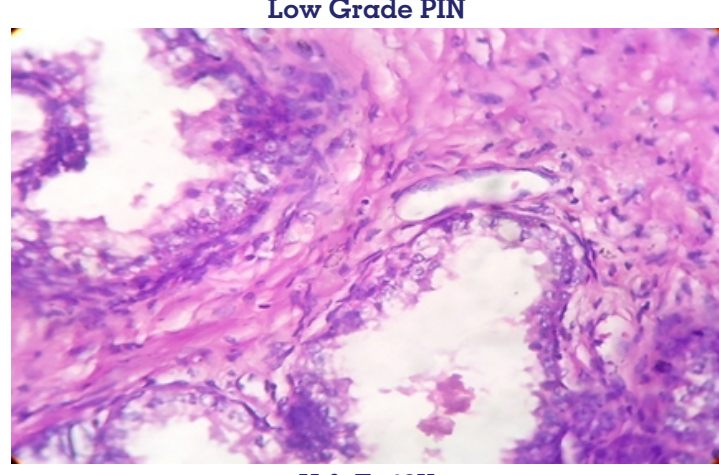

$\mathrm{H} \& \mathrm{E}, 40 \mathrm{X}$

Fin No.4 LGPIN showing enlarged nuclei with small nucleoli in neoplatic cells.

High Grade PIN

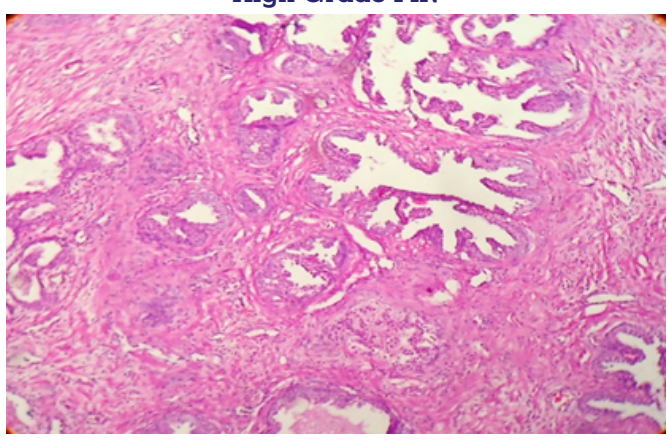

H\&E10X

Fig.no.5. HGPIN showing pronounced epithelial crowding stratification nuclear enlargement with prominent nucleoli and intact basement membrane

High Grade PIN

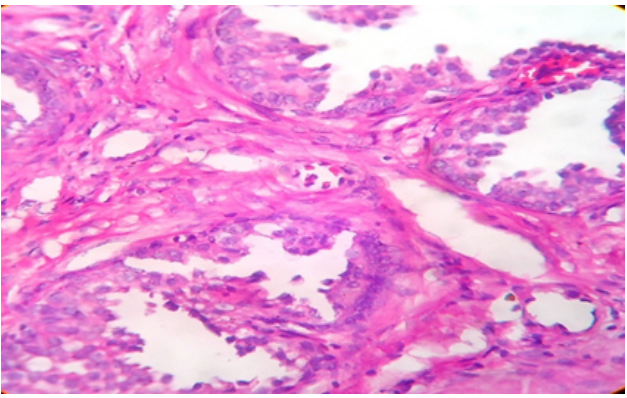

$\mathrm{H} \& \mathrm{E}, 40 \mathrm{X}$

Fin No.6. HGPIN shows cells with enlarged nuclei and prominant nucleoli and intact basement membrane

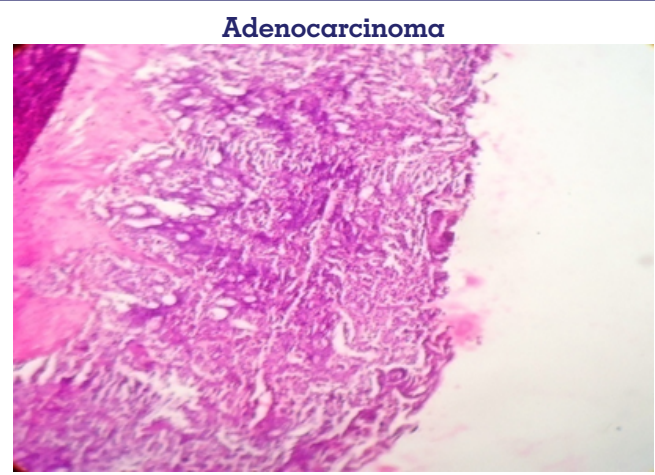

$\mathrm{H} \& \mathrm{E} 10 \mathrm{X}$

Fin No.7. Shows micro acini of small malignant cell infiltrating the prostatic stroma

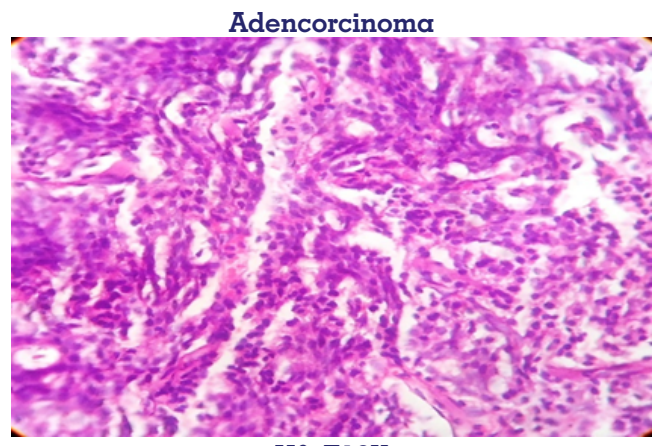

H\& E10X

Fin No.8. Shows back to back microacini and loss fibro muscular sling and malignant cells have enlarged vesicular nuclei and prominente nucleoli basal layar is missed.

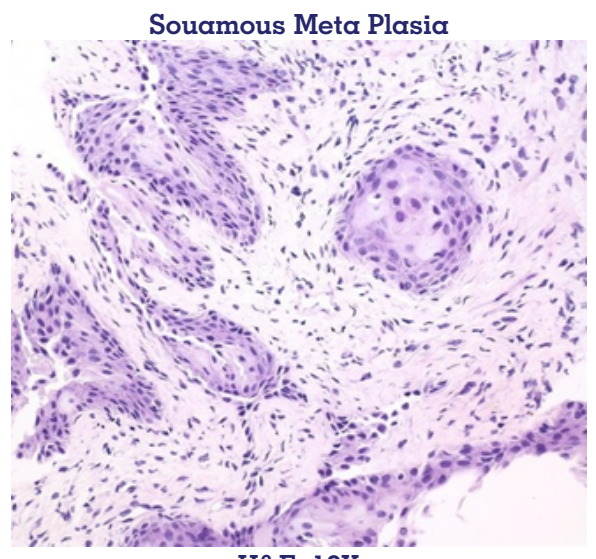

$\mathrm{H} \& \mathrm{E}, 10 \mathrm{X}$

Fig:9 The Normal ductal and glandular epithelial cells of the prostate are transoformed to squaamous ells.

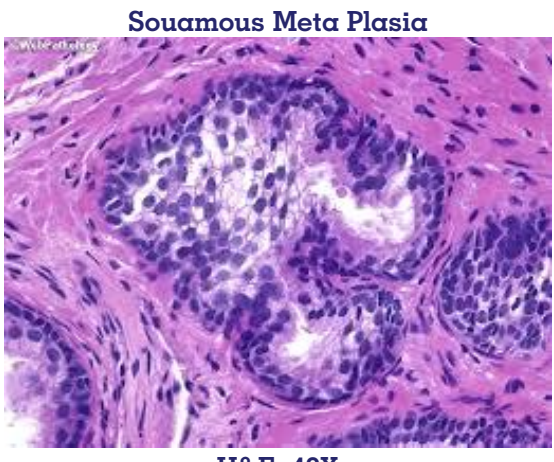

$\mathrm{H} \& \mathrm{E}, 40 \mathrm{X}$

Fig: 10. The Normal ductal and glandular epithelial cells of the prostate are transoformed to squaamous ells. 
REFERENCES

1. Bostwick DG, Amin MB, dundore P et al. Architectural patterns of high grade prostatic intraepithelial neoplasia. Hum Pathol. 1993;24:298-310.

2. Argani P. Epstein Jl inverted (Hobnail) high grade prostatic intraepithelial neoplasia Am J Surg Pathol 2000;24:140-144.

3. Berman DM, Yang, J.Epstein JI Foamy gland high grade prostatic intraepithelial neoplasia. Am J. Surg Pathol. 2000;24:140-144

4. Reyes AO, Swanson PE, Carbone JM, et al. Unusual histologic types of high grade prostatic intraepithelial neoplasia. Am J Surg Pathol. 1997;21:12151222.

5. Chan TY, Epstein Jl Patient and urologist driven second opinion of prostate needle biopsies. J. Urol.2005; 174: 1390-1394.

6. Egevad L.Allsbrook WC, Jr.Epstein Ji. Current practice of diagnosis and reporting of prostate cancer on needle biopsy among genitourinary pathologists. Hum Pathol 2006,37:292-297.

7. Mc Neal JE. Origin and development of carcinoma in the prostate. Cancer 1969; 23:24-34.

8. Bostwick DG Brawer MI. Prostatic intra-epithelial neoplasia and early invasion in prostate cancer. Cancer 1987;59; 788-994.

9. Kronz JD, Sheikh AA, Epstein JI. High grade prostatic intraepithelial neoplasia with adjacent small atypical glands on prostate biopsy. Hum pathol. 2001;32:389-395.

10. Hameed O.Humphrey PA. Stratified epithelium in prostatic adenocarcinoma: a mmic of high gade prostatic intraepithelial neoplasis, Mod Patho, 2006:19899-906.

11. Allam Ck, Bostwick DG Hayes JA, et al. Interobserver variability in the diagnosis of high grade prostatic intraepithelial neoplasia and adenocarcinoma. Mod Pathol. 1996;9:742-751.

12. Fowler JE Jr, Bigler SA, Lynch C, et al. Prospective study of correlations between biopsy detected high grade prostatic intraepithelial neoplasis, serum prostate specific antigen connectratio, and race. Cancer 2001;91-12911296.

13. Abdel-Khalek M, El-Baz M.Ibrahiem E.Predicotors of prostate cancer on extended biopsy in patients with high grade prostatic intraepithelial neoplasia, a multivariate analysis mode. BJU Int. 2004;94:528-533.

14. Joniau S, Goeman L, Pennings, J, et al. Prostatic intraepithelial neoplasis (PIN): importance and clinical management. Eur Urol. 2005;48:379-385.

15. Drago JR, Mostofi Fk, Lee F, Introductory remarl. And workshop summary, Urol 1989:34 (supply)2-3.

16. McNeal JE, Villers A.Redwine EA, et al; Microcarcinoma in the prostate: ts association with duct-acinar dysplasia. Hum pathol. 1991;22:644-652.

17. Haggam MJ, Macoska JA, Wojno KJ, et al. The relationship between prostatic intraepithelial neoplasia and prostate cancer; critical issues. J. Uol $1997 ; 158: 22-22$.

18. Greene DR, Wheeler TM, Egawa S, et al. A comparision of the morphological features of cancer arising in the transition zone and in the peripheral zone of the prostate. J urol. 1991;146:1069-1076.

19. Srodon M, Epstein Jl. Central zone histology of the prostate: a mimicker of high grade prostatic intraepithelial neoplasia. Hum pathol 2002;33:518-523.

20. Ayala AG, Srigly Jr, RoJY,et all Clear cell cribrifor hyperrplasis of prostate. Report of 10 cases. Am J.Surg Pathol. 1986; 10:665-671. 